\title{
Botulinum toxin (Botox)
}

\section{Gary F. Bouloux}

Division of Oral and Maxillofacial Surgery, Department of Surgery, Emory University School of Medicine, Atlanta, GA, USA

Correspondence to: Gary F. Bouloux, DDS, MD, MDSc, FRACDS, FRACDS (OMS), FACS. J. David Allen and Family Professor, Division of Oral and Maxillofacial Surgery, Department of Surgery, Emory University School of Medicine, Atlanta, GA, USA. Email: gfboulo@emory.edu.

\begin{abstract}
Botulinum toxin (Botox) is a neurotoxin produced by the bacterium Clostridium botulinum. There are seven types of Botox (A-G) which bind and cleaves one of several neuronal cellular proteins including SNAP-25, syntaxin or VAMP/synaptobrevin. The net result is the inhibition of the release of acetylcholine (Ach) from the terminal bouton of motor neurons resulting in muscle weakness or paralysis. The duration of action of Botox depends on the time taken for cellular mechanisms to regenerate the cleaved proteins and restore the ability for neuronal Ach release, typically 3-6 months. Botox has several medical indications and is effective in reducing pain and/or muscle activity in chronic migraine, myofascial pain, orofacial movement disorders, neuropathic pain, trigeminal neuralgia (TN) and bruxism. Additionally it can be used to treat sialorrhea and Frey syndrome. The injection technique is very simple and can be performed with or without electromyography depending on the indication. Complications relating to the use of Botox are extremely rare and include allergic reaction and unanticipated weakness/paralysis of adjacent muscles.
\end{abstract}

Keywords: Botulinum toxin (Botox); acetylcholine (Ach); muscle paralysis; orofacial, migraine; myofascial pain; neuropathic pain; trigeminal neuralgia (TN); bruxism; Frey syndrome

Received: 18 July 2020; Accepted: 15 May 2021; Published: 10 March 2022.

doi: $10.21037 /$ fomm-20-42

View this article at: http://dx.doi.org/10.21037/fomm-20-42

\section{Introduction}

Botulinum toxin (Botox) is derived from a gram-positive anaerobic bacteria Clostridium botulinum. There are seven different serotypes (A-G) with a biological effect on neurotransmission. The mechanism of action of Botox involves the following four basic steps:

* Binding of Botox on neuronal presynaptic membrane via synaptic vesicle protein 2 (SV2) and/ or synaptotagmin depending on the serotype;

* Internalization of the Botox via endocytosis;

* Translocation of Botox from the endocytosed vesicle to the neuronal cytosol;

* Cleavage of specific proteins involved in neuroexocytosis including SNAP-25 cleaved by Botox A, E and C; VAMP/synaptobrevin cleaved by Botox B, D, F and G; and syntaxin cleaved by Botox C.

The net result of cleavage of these proteins is inhibition of the formation of the soluble N-ethylmaleimide-sensitive factor attachment protein receptors (SNARE) which are critical for the fusion of the acetylcholine (Ach) containing synaptic vesicles to the presynaptic neuronal membrane. This effectively prevents the release of Ach from the motor endplate at the neuromuscular junction. The net result is muscle paralysis that persists until the internal neuronal proteins (SNAP-25, VAMP and syntaxin) are regenerated over the following 3-6 months.

Botox was originally thought to reduce orofacial pain through inhibition of muscle activity. Current evidence suggests that Botox also possesses analgesic properties as a result of its ability to inhibit the release of substance $\mathrm{P}(\mathrm{SP})$, calcitonin gene-related peptide (CGRP) and transient receptor potential (TRP) vanilloid receptor type 1 (TRPV1). This translates into reduced pain and neurogenic inflammation in the peripheral and central nervous system (CNS). This maybe synergistic with the ability of Botox to block neuromuscular transmission. 


\section{General indications}

Although Botox was initially approved by the FDA in 1989, the list of approved indications has grown to include overactive bladder, headaches, spasticity, dystonia, blepharospasm and hyperhidrosis. It can be administered using an intramuscular or intradermal technique. The use of electromyographic (EMG) monitoring during intramuscular injection is beneficial to facilitate location of motor endplates during injection. The maximum dose for adults is 400 units in a 3-month period or the lesser of 300 units or 8 units $/ \mathrm{kg}$ for pediatric patients. The dose of Botox for any given patient is dependent on the indication for which it is being used. Complications following the use of Botox are exceedingly rare but may include distant spread resulting in asthenia, generalized muscle weakness, diplopia, ptosis, dysphagia, dysphonia, dysarthria, urinary incontinence and breathing difficulties. Botox should not be used in patients with an allergy to Botox or with overlying skin infections.

Orofacial pain can have multiple sources which make diagnosis and treatment challenging. Although temporomandibular disorders (TMD) is a non-specific term, the Diagnostic criteria for temporomandibular disorders (DC/TMD) provides a useful approach to classifying sources of pain within TMD. Axis I describes pain sources and is divided into arthrenous and myogenous sources.

The arthrogenous sources of pain relate to the temporomandibular joint include:

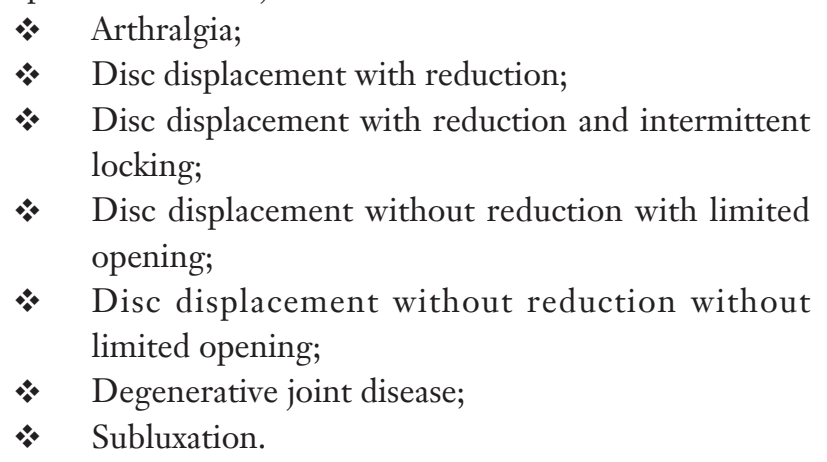

The myogenous sources of pain relate to the masticatory muscles and include:

$* \quad$ Myalgia;
*ocal myalgia;
* Myofascial pain;
* Myofascial pain with referral;
Headache attributed to TMD.

In addition the DC/TMD advocates for the use of screening tools and validated questionnaires to identify Axis II diagnoses such as adverse pain behavior, psychological issues and psychosocial functioning. These factors predict the response to treatment for Axis I diagnoses. It is also important to note that patients presenting with TMD may also suffer from cervical pain, migraine, bruxism, orofacial dystonia, trigeminal neuralgia (TN), fibromyalgia and irritable bowel syndrome. Botox may be beneficial for some of these conditions.

\section{Administraion technique}

Botox comes as a 50-, 100- and 200-unit vial. It needs to be reconstituted with sterile normal saline. Typically this requires the addition of 1,2 or $4 \mathrm{~mL}$ of $\mathrm{NS}$ for the 50-, 100- and 200-unit vials, respectively. This results in a uniform concentration of 5 units of Botox per $0.1 \mathrm{~mL}$. Vials are single use and should be used within 24 hours of reconstitution. Reconstituted vials should be stored at $4{ }^{\circ} \mathrm{C}$ if not used immediately after preparation. The injection site for muscles should target the anatomical location of the greatest density of motor endplates.

\section{Indications in oral and maxillofacial surgery}

\section{Chronic migraine}

Chronic migraines are defined as headache $\geq 15$ days per month with headache lasting more than 4 hours. Botox has been shown to reduce the frequency and intensity of headaches (1-4). The exact mechanism of action is unclear. One thought is that Botox reduces the mechanical sensitivity of cranial muscle nociceptors secondary to reduced glutamate and CGRP. Another potential mechanism is the reduction in SP and CGRP within the trigeminovascular system. There are specific muscles and injection sites that have been shown to be beneficial (Figure 1).

\section{Myofascial pain}

According to the DC/TMD the two validated musclerelated Axis I diagnoses that can be diagnosed with confidence are myalgia and myofascial pain with referral (5). They are diagnosed by history and physical examination (Table 1).

Local myalgia, myofascial pain and headache attributed to TMD remain additional myogenous Axis I diagnoses but the patient's history and physical examination is not generally sufficient to provide an adequate sensitivity or specificity for these conditions. The pathophysiology of 

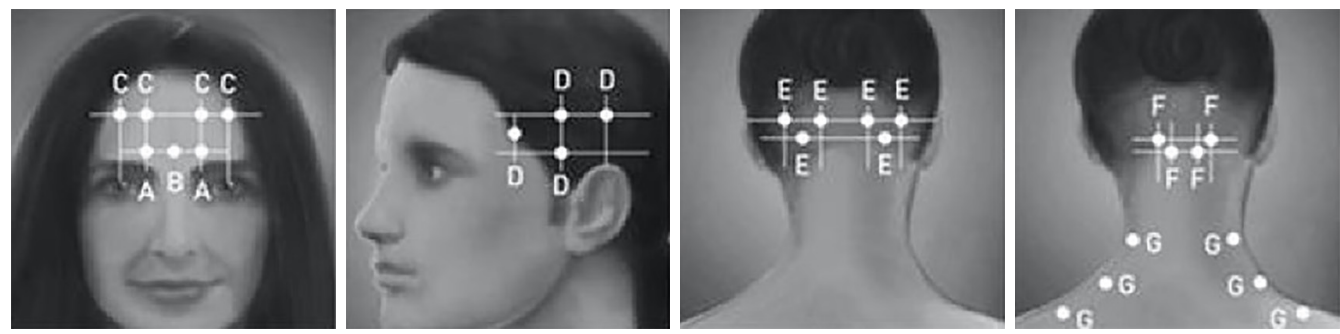

Figure 1 Injection sites for migraines. A, corrugator (10 units divided at 2 sites); B, procerus (5 units at 1 site); C, frontalis (20 units divided at 4 sites); D, temporalis (40 units divided at 8 sites); E, occipitalis (30 units divided at 6 sites); F, cervical (20 units divided at 4 sites); G, trapexius (30 units divided at 6 sites). Adapted from BOTOX ${ }^{\circledR}$ (Allergen, Madison, NJ, USA; on abotulinumtoxin A) Product Insert.

Table 1 Validated Axis I muscle related TMD diagnoses

\begin{tabular}{lll}
\hline History & Physical examination & Disorder \\
\hline $\begin{array}{lll}\text { Pain in a masticatory structure modified by } \\
\text { jaw movement, function or parafunction }\end{array}$ & $\begin{array}{l}\text { Report of familiar pain in the temporalis or masseter muscles } \\
\text { with palpation or jaw opening }\end{array}$ & Myalgia \\
& & Sensitivity $90 \%$ \\
& & Specificity $99 \%$ \\
Pain in a masticatory structure modified by & Report of familiar pain in the temporalis or masseter muscles & Myofascial pain with referral \\
jaw movement, function or parafunction & with palpation or jaw opening that radiates or is referred & Sensitivity $86 \%$ \\
& beyond the muscle boundary & Specificity $98 \%$ \\
\hline
\end{tabular}

TMD, temporomandibular disorders.

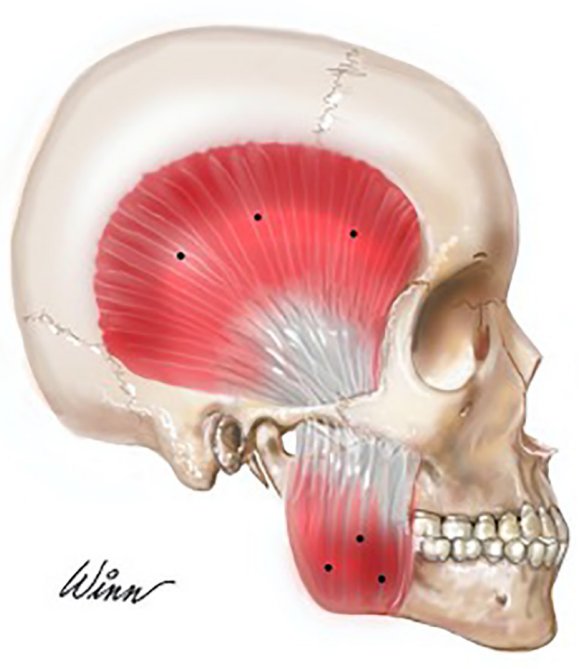

Figure 2 Injection sites for the masseter and temporalis muscles. Total of 50 units Botox in the masseter and 50 units in the temporalis muscle with three injection sites per muscle. Botox, botulinum toxin.
Axis I myogenous pain remains unclear with neurological, myogenous and psychological theories proposed (6). Botox has been shown to reduce pain in the myogenous Axis I diagnoses (7-9). Pain reduction appears to be even greater when bruxism and/or psychiatric stress-related comorbidities exist (10). The most ideal location for injection is at the junction of the lower and middle third of the masseter muscle. The most ideal location for injection of the temporalis muscle is at the midpoint of the belly of the muscle. A total of 50 units of Botox is injected into each masseter and temporalis muscle with an equal number of units at each injection site. This results in a typical dose of 200 units for bilateral masseter and temporalis muscles (Figure 2).

\section{Orofacial movement disorders}

Orofacial movement disorders include orofacial dystonia and orofacial dyskinesia. These conditions can affect multiple orofacial muscles including platysma, orbicularis 
oris, buccinator, genioglossus, geniohyoid, digastric and intrinsic tongue muscles. The net result can be involuntary jaw opening, clenching, tongue thrusting and facial tics. They have the potential to result in TMD when the masseter, temporalis, medial pterygoid muscles are involved $(11,12)$. It may also result in temporomandibular joint dislocation when the lateral pterygoid muscle is involved (13-15). The etiology of these movement disorders is unclear and examination of the central and peripheral nervous systems is typically unremarkable. The treatment is often medications including benzodiazepines, anticholinergic medication, levodopa, bromocriptine and baclofen. Botox remains an effective treatment particularly for focal dystonia and dyskinesia.

The technique for injection is as described for myofascial pain when the temporalis and masseter are involved. Injection for the medial pterygoid is more challenging. There are two basic options both requiring EMG guidance. The first option involves an intra-oral injection using 1.5 -inch needle that is inserted just lateral to the pterygomandibular raphe and parallel to the ramus of the mandible. This is similar to an Inferior alveolar nerve block except that the needle is intentionally directed parallel to the inner aspect of the ramus. The dose of Botox is typically 20 units. An alternate technique that may be considered in thin patients is an extraoral approach from beneath the antegonial notch. It requires the same 1.5-inch needle. The skin and soft tissue immediately beneath the antegonial notch is displaced medially with the index finger of the non-dominant hand. This allows the Botox needle to be inserted from an inferior direction. The needle is kept parallel to the medial aspect of the ramus to ensure the medial pterygoid muscle is correctly targeted. It is technically relatively simple to perform this injection particularly if the needle is bent at about 30 degrees at the hub to allow the hand holding the syringe to be kept lateral with respect to the neck. Complications after Botox injections are uncommon, however with the medial pterygoid muscle being within the infratemporal fossa there is potential for diffusion with resultant dysphonia and dysphagia.

Botox injection for the lateral pterygoid muscle is technically easier. As with the technique for the medial pterygoid muscle there are two approaches and EMG guidance is required. The first and most simple is an intraoral injection immediately behind the maxillary tuberosity. A tongue blade is used to displace the cheek laterally and with the teeth slightly separated and a 30-degree bend of the needle, the needle is directed medially and superiorly behind the tuberosity until the lateral pterygoid plate is encountered (13). Typically $15-25$ units of Botox is adequate (Figure 3A-3D).

The extraoral technique is more challenging. It requires a straight needle to be inserted immediately beneath the articular eminence and through the sigmoid notch. The needle is kept horizontal but directed slightly anteriorly.

\section{Neuropathic pain}

Botox is also known to inhibit neuromodulator and transmitter secretion that may reduce central neuropathic pain. The proposed mechanism of action includes a reduction in the release of excitatory glutamate, SP, and CGRP. Furthermore, Botox reduces the expression of TRPV1 that is associated with capsaicin-evoked and calcium channel responses $(16,17)$.

The injection technique in the management of neuropathic pain is unique in that the Botox is injected subcutaneously in the dermatome overlying the neuropathic pain. The dose varies but generally 5 units of Botox per square centimeter $\left(\mathrm{cm}^{2}\right)$ of skin is adequate. This does not require EMG guidance and can be completed with a tuberculin needle to reduce discomfort during the injections.

\section{$T N$}

TN is not synonymous with neuropathic pain. The etiology of TN remains unclear although compression of the trigeminal nerve root by the superior cerebellar artery is thought to result in focal demyelination and paroxysms of pain. Additional causes include tumors, multiple sclerosis and post-viral syndromes. The mainstay of treatment is medication including carbamazepine, oxycarbamazepine, phenytoin, gabapentin, pregabalin and baclofen. Surgical treatment involves Gasserian ganglion rhizotomy, gamma knife and microvascular decompression (18-20).

The mechanism of action of the Botox is thought to be similar to that of neuropathic pain. The injection technique is also identical. The time to maximal pain reduction for both neuropathic pain and TN appears to be 4-8 weeks. This is much longer than the 1-2 weeks for muscular injection and may reflect the need for retrograde axonal transport to the CNS.

\section{Bruxism}

The beneficial effect of Botox on sleep-related bruxism has been reported $(21,22)$. It appears to reduce the intensity of muscle activity within the masseter and temporalis muscles 

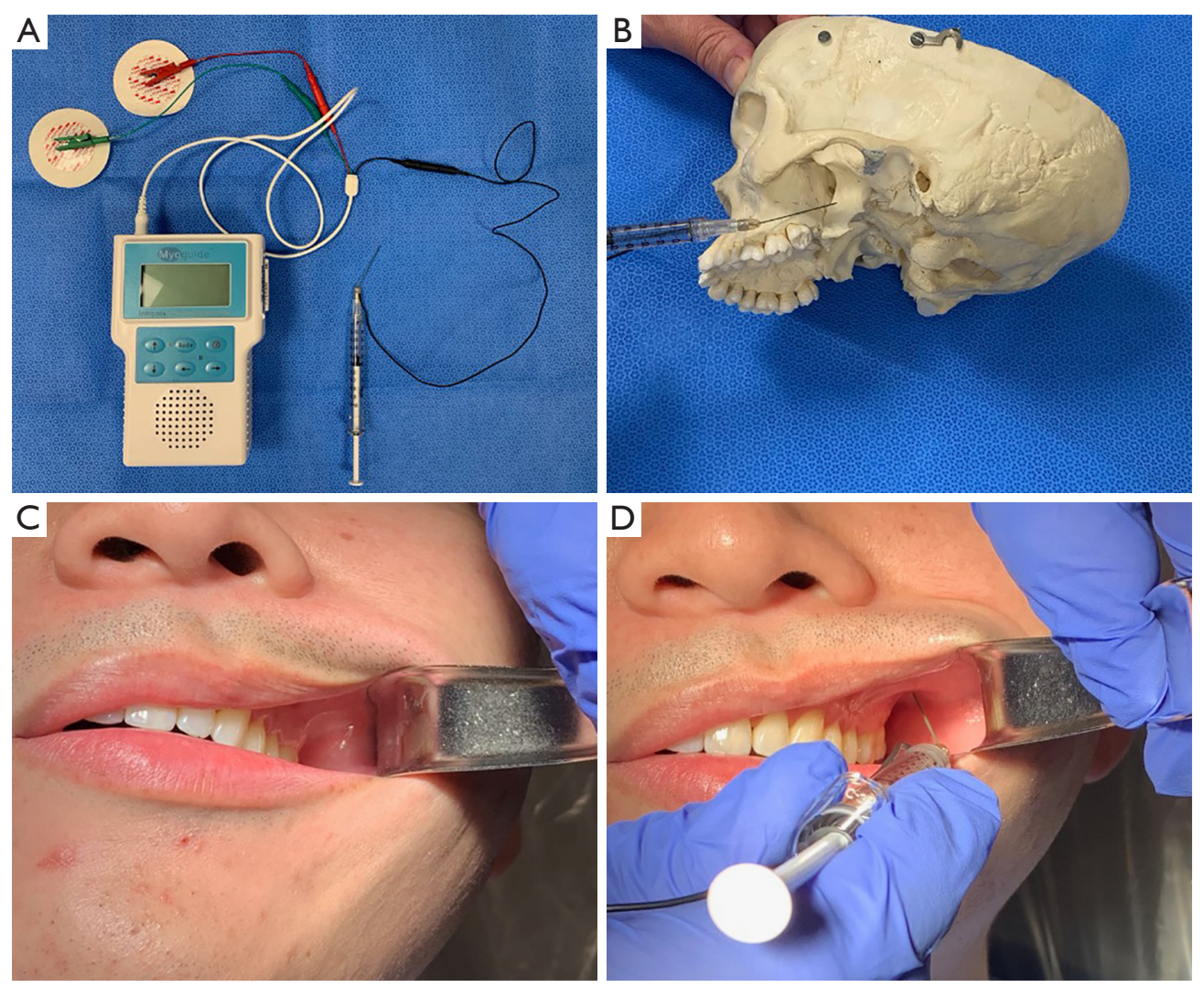

Figure 3 Lateral pterygoid injection technique. (A) Lateral pterygoid injection with electromyography; (B) position of 1.5-inch 25-gauage needle; (C) retraction of cheek and vestibule; (D) syringe and needle position prior to mucosal puncture.

with a reduction in self-reported pain and jaw stiffness. The injection technique and dosing is identical to that for myofascial pain.

\section{Frey syndrome}

Frey syndrome is a rare complication following parotid and temporomandibular joint surgery. It results in gustatory sweating during eating. The parotid gland receives parasympathetic secretory innervation via a complicated neural pathway that involves the auriculotemporal nerve and the release of Ach.

The sweat glands of the skin are innervated by the sympathetic fibers originating from superior cervical ganglion traveling via the same auriculotemporal nerve. Parotid and temporomandibular joint surgery are thought to cause an injury to the auriculotemporal nerve leading to inappropriate parasympathetic innervation of the overlying sweat glands. This can result in profuse sweating during mastication. The diagnosis of Frey syndrome can be made using the minor iodine/starch test. This test will also delineate exact area of skin that is affected. This should be outlined with a skin marker. Botox can be injected subcutaneously using a tuberculin syringe/needle with a dose of 5 units per $\mathrm{cm}^{2}$ of skin involved. The therapeutic effect will be apparent in a week and should last 3-6 months (23).

\section{Sialorrbea}

The excessive production of saliva or the inability to adequately swallow saliva may result in drooling. This is often seen in patients with neurological disorders including those with developmental delay, cerebral palsy, amyotrophic lateral sclerosis, Parkinson's disease, cerebrovascular accident and traumatic brain injury. Antisialogogues such as glycopyrrolate have limited efficacy and result in systemic side effects. Surgical procedures including salivary gland duct ligation and sialodochoplasty to reposition ducts has also been described. The use of Botox to reduce salivation has grown in popularity with promising results (24-26). The 
technique for parotid and submandibular gland injection is relatively simple. The use of ultrasound to identify the precise location of the gland and appropriate intraglandular injection is encouraged. The ideal dose varies depending on the gland size and the severity of hypersalivation and drooling. Doses from 5 to 40 units per gland have been reported.

\section{Acknowledgments}

Funding: None.

\section{Footnote}

Provenance and Peer Review: This article was commissioned by the Guest Editors (Stephen Feinberg and Louis Mercuri) for the series "Temporomandibular Joint Disorders Diagnosis and Management - What Does the Future Hold?" published in Frontiers of Oral and Maxillofacial Medicine. The article has undergone external peer review.

Conflicts of Interest: The author has completed the ICMJE uniform disclosure form (available at https://fomm. amegroups.com/article/view/10.21037/fomm-20-42/coif). The series "Temporomandibular Joint Disorders Diagnosis and Management - What Does the Future Hold?" was commissioned by the editorial office without any funding or sponsorship. The author has no other conflicts of interest to declare.

Ethical Statement: The author is accountable for all aspects of the work in ensuring that questions related to the accuracy or integrity of any part of the work are appropriately investigated and resolved.

Open Access Statement: This is an Open Access article distributed in accordance with the Creative Commons Attribution-NonCommercial-NoDerivs 4.0 International License (CC BY-NC-ND 4.0), which permits the noncommercial replication and distribution of the article with the strict proviso that no changes or edits are made and the original work is properly cited (including links to both the formal publication through the relevant DOI and the license). See: https://creativecommons.org/licenses/by-nc-nd/4.0/.

\section{References}

1. Gazerani P, Au S, Dong X, et al. Botulinum neurotoxin type A (BoNTA) decreases the mechanical sensitivity of nociceptors and inhibits neurogenic vasodilation in a craniofacial muscle targeted for migraine prophylaxis. Pain 2010;151:606-16.

2. Kleen JK, Levin M. Injection therapy for headache and facial pain. Oral Maxillofac Surg Clin North Am 2016;28:423-34.

3. Frampton JE. OnabotulinumtoxinA $\left(\right.$ BOTOX $\left.^{\circledR}\right)$ : a review of its use in the prophylaxis of headaches in adults with chronic migraine. Drugs 2012;72:825-45.

4. Luvisetto S, Gazerani P, Cianchetti C, et al. Botulinum toxin type a as a therapeutic agent against headache and related disorders. Toxins (Basel) 2015;7:3818-44.

5. Schiffman E, Ohrbach R. Executive summary of the Diagnostic Criteria for Temporomandibular Disorders for clinical and research applications. J Am Dent Assoc 2016;147:438-45.

6. Fallah HM, Currimbhoy S. Use of botulinum toxin A for treatment of myofascial pain and dysfunction. J Oral Maxillofac Surg 2012;70:1243-5.

7. Sunil Dutt C, Ramnani P, Thakur D, et al. Botulinum toxin in the treatment of muscle specific Oro-facial pain: a literature review. J Maxillofac Oral Surg 2015;14:171-5.

8. Baker JS, Nolan PJ. Effectiveness of botulinum toxin type A for the treatment of chronic masticatory myofascial pain: a case series. J Am Dent Assoc 2017;148:33-9.

9. Sidebottom AJ, Patel AA, Amin J. Botulinum injection for the management of myofascial pain in the masticatory muscles. A prospective outcome study. Br J Oral Maxillofac Surg 2013;51:199-205.

10. Connelly ST, Myung J, Gupta R, et al. Clinical outcomes of Botox injections for chronic temporomandibular disorders: do we understand how Botox works on muscle, pain, and the brain? Int J Oral Maxillofac Surg 2017;46:322-7.

11. Bakke M, Baram S, Dalager T, et al. Oromandibular dystonia, mental distress and oro-facial dysfunction-A follow-up 8-10 years after start of treatment with botulinum toxin. J Oral Rehabil 2019;46:441-9.

12. Clark GT, Ram S. Orofacial movement disorders. Oral Maxillofac Surg Clin North Am 2016;28:397-407.

13. Mendes RA, Upton LG. Management of dystonia of the lateral pterygoid muscle with botulinum toxin $\mathrm{A}$. Br J Oral Maxillofac Surg 2009;47:481-3.

14. Renapurkar SK, Laskin DM. Injectable agents versus surgery for recurrent temporomandibular joint dislocation. Oral Maxillofac Surg Clin North Am 2018;30:343-9.

15. Yoshida K. Botulinum neurotoxin injection for the treatment of recurrent temporomandibular joint 
dislocation with and without neurogenic muscular hyperactivity. Toxins (Basel) 2018;10:174.

16. Park J, Chung ME. Botulinum toxin for central neuropathic pain. Toxins (Basel) 2018;10:224.

17. Moreau N, Dieb W, Descroix V, et al. Topical review: potential use of botulinum toxin in the management of painful posttraumatic trigeminal neuropathy. J Oral Facial Pain Headache 2017;31:7-18.

18. Burmeister J, Holle D, Bock E, et al. Botulinum neurotoxin type A in the treatment of classical Trigeminal Neuralgia (BoTN): study protocol for a randomized controlled trial. Trials 2015;16:550.

19. Castillo-Álvarez F, Hernando de la Bárcena I, Marzo-Sola ME. Botulinum toxin in trigeminal neuralgia. Med Clin (Barc) 2017;148:28-32.

20. Li S, Lian YJ, Chen Y, et al. Therapeutic effect of Botulinum toxin-A in 88 patients with trigeminal neuralgia with 14-month follow-up. J Headache Pain 2014;15:43.

21. De la Torre Canales G, Camara-Souza MB, do Amaral $\mathrm{CF}$, et al. Is there enough evidence to use botulinum toxin injections for bruxism management? A systematic

doi: 10.21037/fomm-20-42

Cite this article as: Bouloux GF. Botulinum toxin (Botox). Front Oral Maxillofac Med 2022;4:4. literature review. Clin Oral Investig 2017;21:727-34.

22. Shim YJ, Lee MK, Kato T, et al. Effects of botulinum toxin on jaw motor events during sleep in sleep bruxism patients: a polysomnographic evaluation. J Clin Sleep Med 2014;10:291-8.

23. Jansen S, Jerowski M, Ludwig L, et al. Botulinum toxin therapy in Frey's syndrome: a retrospective study of 440 treatments in 100 patients. Clin Otolaryngol 2017;42:295-300.

24. Alvarenga A, Campos M, Dias M, et al. BOTOX-A injection of salivary glands for drooling. J Pediatr Surg 2017;52:1283-6.

25. Sridharan K, Sivaramakrishnan G. Pharmacological interventions for treating sialorrhea associated with neurological disorders: a mixed treatment network metaanalysis of randomized controlled trials. J Clin Neurosci 2018;51:12-7.

26. Weitzman RE, Kawai K, Nuss R, et al. A 10-year retrospective review of botulinum toxin injections and surgical management of sialorrhea. Cureus 2020;12:e7916. 